\title{
The Determination of Surface Salinity With the European SMOS Space Mission
}

\author{
Jordi Font, Gary S. E. Lagerloef, David M. Le Vine, Fellow, IEEE, Adriano Camps, Senior Member, IEEE, and \\ Ouan-Zan Zanifé
}

\begin{abstract}
The European Space Agency Soil Moisture and Ocean Salinity (SMOS) mission aims at obtaining global maps of soil moisture and sea surface salinity from space for large-scale and climatic studies. It uses an L-band (1400-1427 MHz) Microwave Interferometric Radiometer by Aperture Synthesis to measure brightness temperature of the earth's surface at horizontal and vertical polarizations $\left(T_{\mathrm{h}}\right.$ and $\left.T_{\mathrm{v}}\right)$. These two parameters will be used together to retrieve the geophysical parameters. The retrieval of salinity is a complex process that requires the knowledge of other environmental information and an accurate processing of the radiometer measurements. Here, we present recent results obtained from several studies and field experiments that were part of the SMOS mission, and highlight the issues still to be solved.
\end{abstract}

Index Terms-Microwave radiometry, oceanography, salinity.

\section{INTRODUCTION}

$\mathbf{T}$ HE Soil Moisture and Ocean Salinity (SMOS) mission is the second of the European Space Agency (ESA) Earth Explorer Opportunity Missions [1], within the ESA Living Planet Programme. SMOS was proposed by an international team of land and ocean scientists and technologists. It was selected by ESA in 1999 and is scheduled for launch in early 2007. It uses a dual polarized L-band interferometric radiometer called Microwave Interferometric Radiometer by Aperture Synthesis (MIRAS) [2] to retrieve both geophysical variables (Fig. 1). The brightness temperatures $\left(T_{\mathrm{h}}\right.$ and $\left.T_{\mathrm{v}}\right)$ measured by the radiometer are linked to salinity through the dielectric constant of the sea water. The dependence on salinity (conductivity) increases with decreasing frequency, and low microwave frequencies are needed to detect changes in salinity [3]. The spectral window at L-band set aside for passive use only $(1400-1427 \mathrm{MHz})$ provides sufficient sensitivity with modern radiometers for remote sensing [3], [4]. Over land, at the same frequency MIRAS can also be used to determine soil moisture [5]. The principle of aperture synthesis employed by

Manuscript received September 30, 2003; revised May 10, 2004. This work was supported in part by the Spanish National Program on Space under Grants ESP2001-4523-PE, ESP2003-11604-E, and ESP2003-11648-E.

J. Font is with the Institut de Ciències del Mar, CMIMA-CSIC, 08003

Barcelona, Spain (e-mail: jfont@icm.csic.es).

G. S. E. Lagerloef is with Earth and Space Research, Seattle, WA 98102 USA (e-mail: lager@esr.org).

D. M. Le Vine is with the Microwave Sensors Branch, Laboratory for Hydrospheric Processes, National Aeronautics and Space Administration Goddard Space Flight Center, Greenbelt, MD 20771 USA (e-mail: David.M.LeVine@nasa.gov).

A. Camps is with the Department Teoria del Senyal i Comunicacions, Universitat Politècnica de Catalunya, 08034 Barcelona, Spain.

O.-Z. Zanifé is with the Space Oceanography Division, Collecte, Localisation, Satellites (CLS), 31526 Ramonville Saint-Agne, France.

Digital Object Identifier 10.1109/TGRS.2004.834649 the radiometer on SMOS is similar to earth rotation synthesis developed in radio astronomy [6]. Aperture synthesis permits the use of thinned antenna arrays as compared to an equivalent real aperture antenna and, therefore, has advantages for use in a satellite mission. The radiometer on SMOS is dual-polarized (with an optional fully polarimetric mode) and has multiangular imaging capabilities that are crucial for the development of new and more efficient retrieval methods [7] (Fig. 2).

In spite of the fact that sea surface salinity (SSS) is crucial to understanding ocean dynamics and its role in the water cycle and climate system, there is not an observing system to provide regular measurements of SSS over all the world's ocean. While nowadays ocean general circulation models assimilate sea surface temperature and height data measured from satellites, for salinity they depend on relaxation to climatological values. Even these are scarce, since $30 \%$ of the ocean surface has never been sampled for salinity in 100 years of data collection [4].

Even though the window at L-band is the best choice for salinity remote sensing, the measurement of SSS requires special care: even in the ideal case (smooth surface), the sensitivity of brightness temperature to SSS is low (from $0.8 \mathrm{~K}$ to $0.2 \mathrm{~K}$ per psu, depending on ocean temperature, radiometer incidence angle, and polarization [8]). In addition, there are technical difficulties to achieve the very accurate radiometric calibration and high stability necessary. It is impossible to fully account for all geophysical parameters that modify $T_{\mathrm{h}}$ and $T_{\mathrm{v}}$ (as surface roughness and atmospheric effects). Also, it will be necessary to average the SMOS pixel (on the order of $30 \times 30 \mathrm{~km}^{2}$ to $50 \times 50 \mathrm{~km}^{2}$ ) in both space and time to reduce measurement noise. As a result, the mission will focus only on large-scale oceanography. However, several phenomena extremely relevant for large-scale and climatic studies can benefit from the SMOS observational approach: barrier layer effects on tropical Pacific heat flux, halosteric adjustment of heat storage from sea level, North Atlantic thermohaline circulation, surface freshwater flux balance, etc. These require an obtainable accuracy of 0.1-0.4 psu over $100 \times 100 \mathrm{~km}^{2}$ to $300 \times 300 \mathrm{~km}^{2}$ in $10-30$ days [9], [10].

\section{SMOS SALinity ObJeCtives AND SCIENTIFIC REQUIREMENTS}

Given the considerations above, the objectives for ocean salinity mapping with SMOS were defined as follows [11]:

- Improve seasonal to interannual [El Niño-Southern Oscillation] climate predictions: This involves the use of ocean salinity data to initialize and improve the coupled 

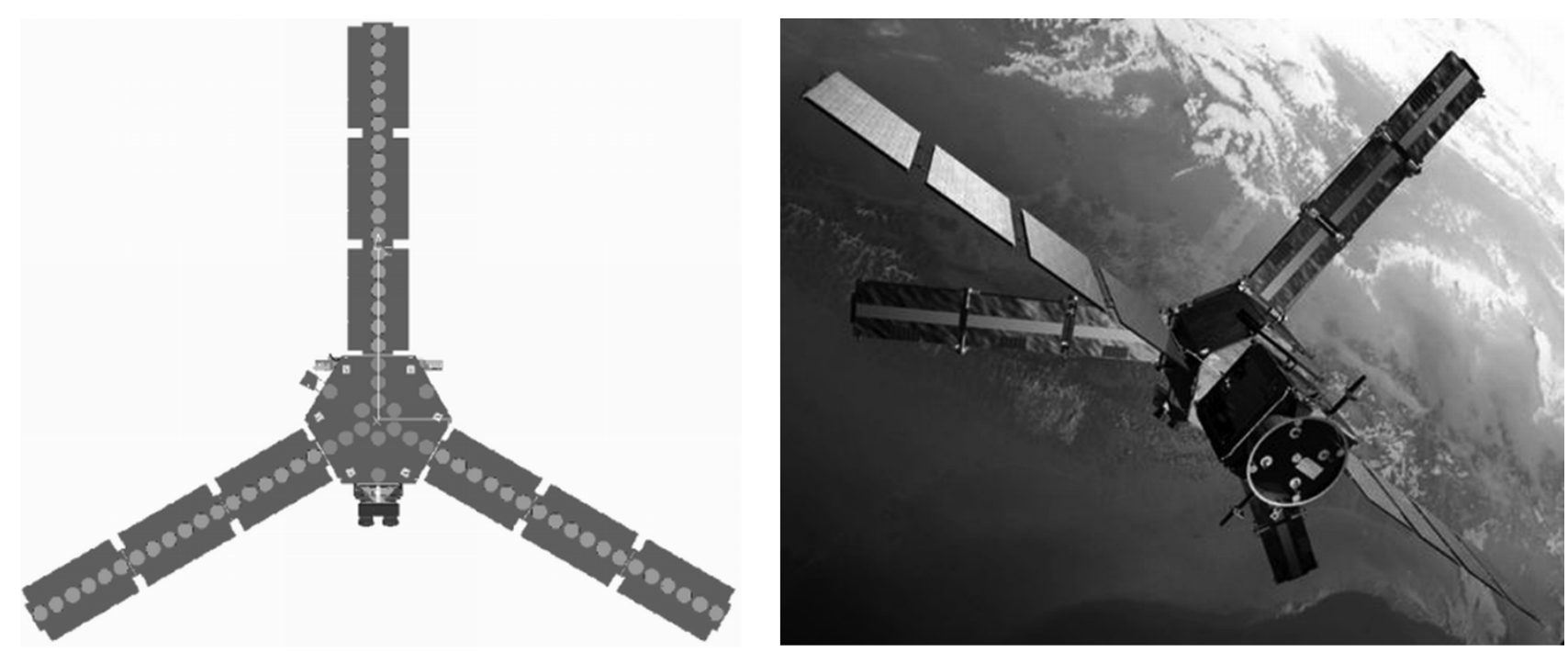

Fig. 1. (Left) Design of the Y-shaped MIRAS radiometer with 69 antenna elements (from EADS CASA Espacio). (Right) Artist's view of the SMOS spacecraft (from ESA Medialab).

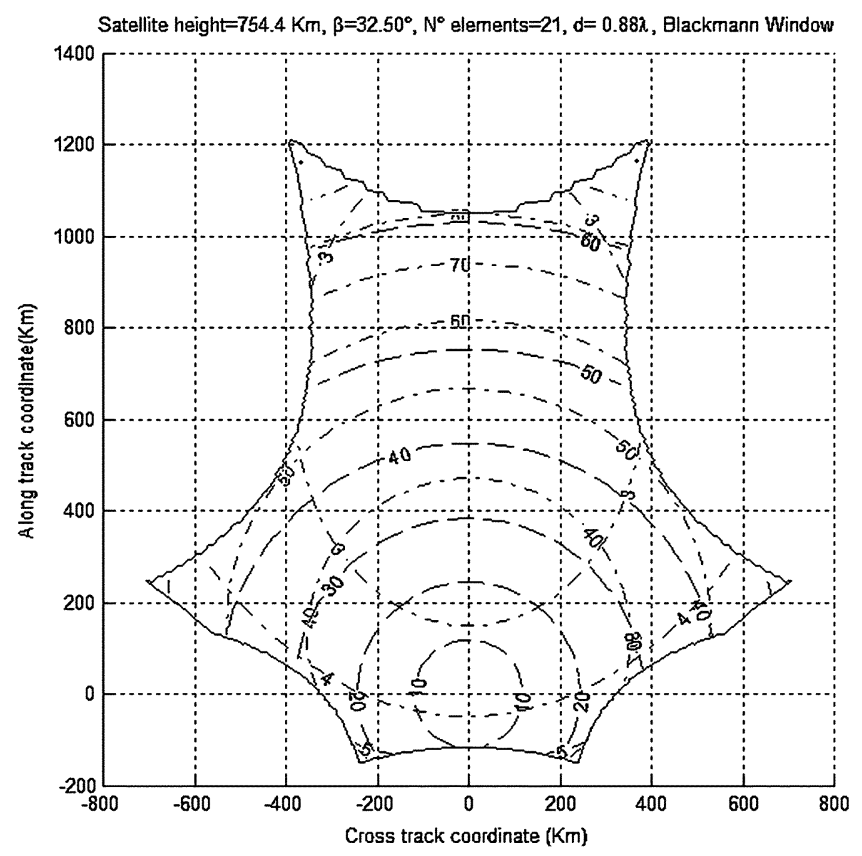

Fig. 2. SMOS instantaneous alias-free field-of-view (irregular curved hexagon) illustrates the multiangular and spatially variable nature of the measurements. Incidence angle (dashed lines) ranges from $0^{\circ}$ to $65^{\circ}$, spatial resolution (dashed-dotted lines) from $32-100 \mathrm{~km}$, and radiometric sensitivity (dashed-dotted) from $2.60 \mathrm{~K}$ at boresight to $5 \mathrm{~K}$. As the satellite advances, a single spot is seen in successive snapshots under different angles and spatial and radiometric resolutions depending on its position within the instrument field of view. The figure was generated by the SMOS End-to-end Performance Simulator (UPC).

climate forecast models, and to study and model the role of freshwater flux in the formation and maintenance of barrier layers and mixed layer heat budget in the tropics.

- Improve the estimates of ocean rainfall and thus the global hydrologic budgets: The "ocean rain gauge" concept shows considerable promise for reducing uncertainties of the surface freshwater flux on climate time scales, given ocean salinity observations, surface velocities, and adequate mixed layer modeling.
- Monitor large-scale salinity events: This may include ice melt, major river runoff events, or monsoons. In particular, tracking interannual ocean salinity variations in the Nordic Seas is vital to long time scale climate prediction and modeling.

- Improve monitoring of sea surface salinity variability: This goal in this case is to better understand and characterize the distribution of biogeochemical parameters in the surface of the ocean.

The Global Ocean Data Assimilation Experiment (GODAE), a pilot experiment set up by the Ocean Observations Panel for Climate, aims at demonstrating the feasibility and practicality of real-time global ocean modeling and data assimilation systems, both in terms of their implementation and in terms of their utility [12]. Following recommendations of the Ocean Observing System Development Panel, the proposed GODAE accuracy requirement for satellite SSS is specified as $0.1 \mathrm{psu}$ for a ten-day and $2^{\circ} \times 2^{\circ}$ resolution for global ocean circulation studies. Considering the exploratory nature of the SSS measurement with SMOS, the GODAE open-ocean requirement represents a technically challenging objective. Incomplete knowledge of image reconstruction errors, their correlation characteristics, and calibration stability represents uncertainties on the capability of SMOS in achieving these requirements, particularly in higher latitudes where the sensitivity to SSS is lower because of the lower SST. However, it will be possible to average data over 30 days or longer periods for many climate studies and thereby further reduce random measurement noise. Ten-day resolution will be less accurate, but may be retained for certain operational applications related to GODAE. Monthly averages over $100 \times 100 \mathrm{~km}^{2}$ boxes would give data comparable to the standard climatologies [13], but with time dependence, which is not available from current climatologies.

Many projects have been carried out during the period 2000-2003 to increase our knowledge of the salinity retrieval from L-band measurements, and especially the effects of the different geophysical factors in this retrieval. Several studies and field experiments have been conducted, including those 
sponsored by ESA during the SMOS extended phase A, by national agencies in Europe, and in the U.S. in support of the Aquarius/SAC-D mission (also to measure SSS). Significant progress has been made in many aspects of the problem. These include precise determinations of sea water permittivity through laboratory experiments; the improvement of sea surface emissivity models, the analysis of perturbing geophysical factors such as surface roughness, sea foam, or rain; the different options and steps of processing radiometric data to retrieve salinity; and the impact of assimilating the expected SMOS salinity products in ocean circulation models. However, several issues still need to be addressed, some of them related to the general process of inverting radiometric data influenced by environmental parameters, and others related to specific instrumental or data processing aspects for the SMOS configuration [14] case. In this paper, we describe the main results from recent studies and field experiments and report on the present situation on issues still to be solved.

\section{DISCUSSION OF RECENT RESULTS}

\section{A. Sea Water Dielectric Constant}

The retrieval of salinity from passive (i.e., radiometric) measurements depends on the relationship of the measured parameter, brightness temperature, $T_{\mathrm{b}}$, to variables such as frequency, polarization, incidence angle, sea surface temperature, and surface roughness, as well as salinity [4].

The dependence of $T_{\mathrm{b}}$ on salinity is through the dielectric constant $\left(\varepsilon_{r}\right)$. Hence, the first step is to have an accurate model of the dependence of $\varepsilon_{r}$ on salinity and temperature at L-band. At present, there are two principal models available: one derived in 1977 by Klein and Swift [3] from measurements on $\mathrm{NaCl}$ solutions (which exhibit a different conductivity than the sea water equivalent solution with the same concentration), and one by Ellison et al. in 1998 [15] from measurements with sea water, but at higher frequencies $(3-90 \mathrm{GHz})$ and extrapolated to L-band. When applied to remote sensing of salinity at L-band, one finds differences on the order of $1 \mathrm{~K}$ between them [16], which is larger than the desired measurement accuracy. This and the lack of measurements at the L-band frequency $(1.413 \mathrm{GHz})$ to be employed in SMOS (and Aquarius) suggests a need to obtain an updated model from sea water measurements at L-band.

Experiments with Passive and Active L-band and S-band (PALS) airborne instrument [17]) were made in October to November 2001 in a sea water pond at the Jet Propulsion Laboratory (JPL), Pasadena, CA, to examine the radiometric response to salinity and temperature. The instrument observed the surface at a constant $45^{\circ}$ incidence angle, and measurements were made at horizontal $(\mathrm{H})$ and vertical $(\mathrm{V})$ polarizations. The measurements were repeated for several days at fixed salinities of 25,35 , and $40 \mathrm{psu}$, and temperature ranging from $8{ }^{\circ} \mathrm{C}$ to $32{ }^{\circ} \mathrm{C}$. The curves of $T_{\mathrm{b}}$ versus water temperature were averaged after adjusting biases to correct for changes in background radiation and sidelobes. The signal varied by 0.3 $\mathrm{K}$ peak-to-peak with an rms value of $\sim 0.06 \mathrm{~K}$. The shape of the curves as a function of temperature was in good agreement with the Klein and Swift model [3] except at the warmest and coldest extremes [18].
New measurements of the dielectric constant at the correct L-band frequency $(1.413 \mathrm{GHz})$ were made during spring-summer 2002 at Universitat Politècnica de Catalunya (UPC, Barcelona) in the range $0-40$ psu and $0{ }^{\circ} \mathrm{C}$ to $40{ }^{\circ} \mathrm{C}$, and in 2003 in the U.S. at the George Washington University (Washington, DC) at selected values of salinity and temperature. The UPC group employed a waterfilled waveguide and the GWU group a resonant cylindrical cavity. The UPC group [19] fitted their measurements using the parameterization adopted by Klein and Swift [3]. The trends (i.e., as a function of salinity and temperature) tend to be in reasonable agreement with the Klein-Swift model, although the differences are larger than tolerable error, assuming a measurement goal of $0.1 \mathrm{psu}$. The results are in closer agreement with the Klein and Swift model than the Ellison et al. model [15] and exhibit a more linear trend versus temperature. In an effort to reduce error, the UPC measurements have been repeated during spring 2004 with a different experimental setup that uses a strip-like transmission line filled with sea water. Preliminary results are now closer to Klein and Swift (S. Blanch, personal communication). Results of the measurements at GWU [20] are between the 2002 UPC and Klein and Swift models, sometimes in better agreement with one than the other (i.e., agree better in the real or imaginary part). Unfortunately, the differences among these measurements (UPC, GWU, Klein-Swift) are larger than tolerable given a measurement goal of $0.1 \mathrm{psu}$, especially in the imaginary part. Until a new model is adequately contrasted and widely accepted, the SMOS and Aquarius communities have agreed to use the Klein and Swift model.

\section{B. L-Band Sea Surface Emissivity Forward Models}

Emission from the ocean surface depends on the structure (e.g., wave-induced roughness) of the surface, including the effects of foam, rain, and other factors that may modify this structure at different spatial scales. The effects at L-band are not well known. Models usually used at higher microwave frequencies are currently being updated and validated at L-band. The ability to correctly predict emissivity depends on the accuracy of the statistical description of the sea surface and the electromagnetic scattering model used to compute the emissivity. Different studies have been made to examine the sensitivity of $T_{\mathrm{b}}$ to wind velocity, SST, SSS, and the impact of different parameterizations for the wave spectrum and effects of foam [16], [21]-[24]. This was done using different methods [25] for solving the electromagnetic problem (small slope approximation (SSA)/small perturbation method [26], [27], two-scale models [28], [29], Kirchhoff [30]-[32], integral equation model [33], [34]), different sea surface spectra [35]-[37], different models for the dielectric constant [3], [15], and different sea foam emissivity models [38]-[42]. Although there are no strong differences between them, a theoretical study by Reul and Chapron (unpublished, report included in [43] has concluded that SSA combined with an appropriate statistical model for the rough sea surface description is the most accurate first-order asymptotic solution to simulate $T_{\mathrm{b}}$ from the rough sea surface at L-band, giving a better understanding of the underlying physics. While two-scale (composite-surface) models are also known to provide accurate results for sea 


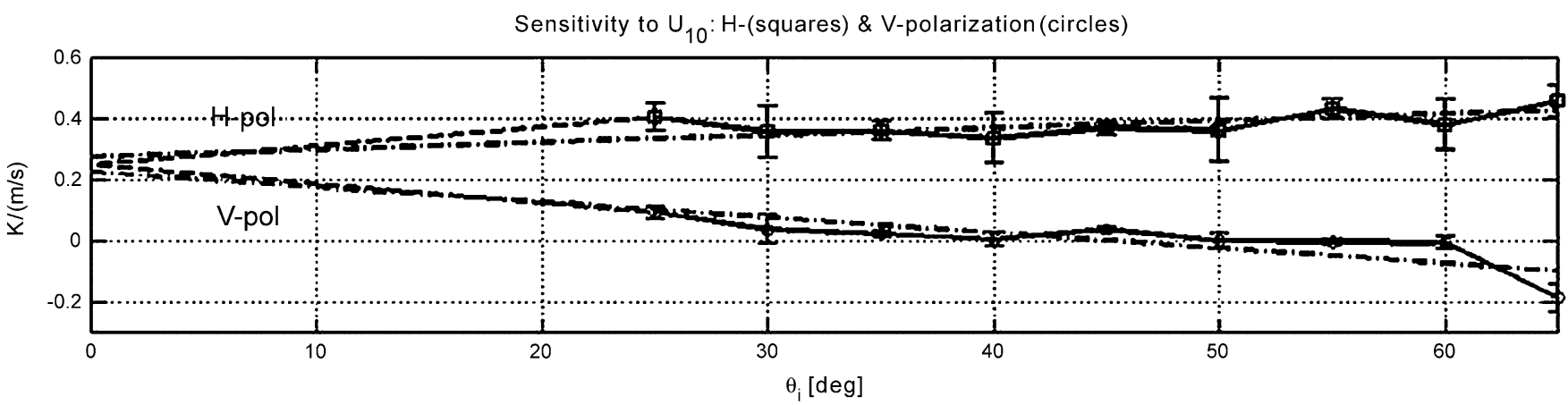

Fig. 3. WISE 2001 experiment. Derived wind speed sensitivity as (solid line) a function of polarization and incidence angle, associated $\pm 1 \sigma$ error bars, (dashed-dotted lines) extrapolation to nadir and (dashed-dotted lines) linear fit. Only data points with $U_{10}>2 \mathrm{~m} / \mathrm{s}$ have been retained (with atmospheric instability correction). From Camps et al. [46].

surface emissivity, they introduce a scale-dividing parameter separating small- and large-scale components of sea surface roughness, which can be arbitrarily chosen within wide limits. The SSA is independent on such free-tuning parameter. The semiempirical spectrum model by Kudryavtsev et al. [37] provides a physically consistent statistical description at decimetric waves (major surface emitters at L-band), and when used jointly with the SSA model, it seems to provide accurate emissivity predictions, a conclusion that requires further experimental verification. A new asymptotic scattering theory, which accounts for surface curvature, has been developed recently by Elfouhaily et al. [44]. This curvature formulation unifies the electromagnetic models and explains polarization sensitivity to roughness. It is necessary to investigate these new developments in the SMOS context.

The radiometric data from the Wind and Salinity Experiment (WISE) [45], [46] are an important step forward in the determination of the sensitivity of $T_{\mathrm{b}}$ to surface roughness (usually parameterized through wind speed). WISE, performed for ESA during the SMOS scientific preparatory studies, consisted in two series of radiometric plus oceanographic measurements from an oil platform in the northwest Mediterranean in autumn 2000 and 2001. The analysis of the full dataset reveals that wind stress and sea state (significant wave height) recorded during the experiment are often correlated. In this case, wind intensity and direction can be used to describe the sea state most of the time. However, in some situations, as in presence of swell, this is no longer valid. In these cases the predicted brightness temperature, assuming a fully developed sea with the local wind speed, and the actual one can differ by an amount comparable to the SSS signature [45], [47], and a different parameterization for surface roughness is needed.

WISE results confirm Hollinger's [48] conclusions regarding the dependence on wind speed, despite the "large" error bars [46] that are attributed to errors in the conversion from 2.6 and 69 to $10-\mathrm{m}$ height wind speed, to the fact that the sea surface roughness cannot be properly modeled by solely the wind speed, and by the so-called $T_{\mathrm{b}}$ fluctuations [49], of yet unknown origin. The processing of the WISE data reveals a sensitivity to wind speed $U_{10}$ (Fig. 3) extrapolated at nadir of $\sim 0.23 \mathrm{~K} /(\mathrm{m} / \mathrm{s})$, or somewhat higher $\sim 0.25 \mathrm{~K} /(\mathrm{m} / \mathrm{s})$ when the atmospheric instability or only the measurements corresponding to $U_{10}>2 \mathrm{~m} / \mathrm{s}$ are accounted for [46]. These values at nadir have to be taken with care, as WISE measurements (from a radiometer located at $32 \mathrm{~m}$ above sea level) could not be done with incidence angles lower than $25^{\circ}$ and a linear extrapolation may not be correct. Indeed, Webster et al. [50] performed airborne radiometric measurements at $1.4 \mathrm{GHz}$ at nadir incidence and reported a sensitivity of $0.16 \mathrm{~K} /(\mathrm{m} / \mathrm{s})$. This sensitivity increases at H-polarization up to $\sim 0.5 \mathrm{~K} /(\mathrm{m} / \mathrm{s})$ at $65^{\circ}$ and decreases at V-polarization down to $\sim-0.2 \mathrm{~K} /(\mathrm{m} / \mathrm{s})$ at $65^{\circ}$, with a zero-crossing around $55^{\circ}$ to $60^{\circ}$. These results are in agreement with the SSA method using Durden-Vesecky [35] times 2 and Elfouhaily et al. [36] sea spectra. It is very likely that the computed wind speed sensitivities below $2 \mathrm{~m} / \mathrm{s}$ are erroneous due to inaccuracies in the theoretical sea surface spectra. Although errors could simply occur because at such low wind speeds, the wind/sea-state relationships are not self-similar but very much dependent on the atmospheric turbulence variability, atmospheric stratification effects, and even inversion height (related to size of large convective elements). The presence of swell has larger relative importance in low wind speed conditions. Low wind speed conditions are simply difficult situations to characterize.

The WISE results also show a modulation of the instantaneous brightness temperatures due to wave slopes (and also foam), which makes the standard deviation of this modulation increase with wind speed at a rate of $\sim 0.1-0.15 \mathrm{~K} /(\mathrm{m} / \mathrm{s})$, depending on polarization, and very weakly on incidence angle. Also a $T_{\mathrm{b}}$ sensitivity analysis with respect to significant wave height has been performed. A sensititivity of $\sim 1 \mathrm{~K} / \mathrm{m}$ is extrapolated at nadir, increasing at $\mathrm{H}$-polarization up to $\sim 1.5 \mathrm{~K} / \mathrm{m}$ at $65^{\circ}$, and decreasing at $\mathrm{V}$-polarization down to $-0.5 \mathrm{~K} / \mathrm{m}$ at $65^{\circ}$. In addition, a small azimuthal modulation $\sim 0.2-0.3 \mathrm{~K}$ peak to peak has been observed for low to moderate wind speeds, in reasonable agreement with numerical models. However, very large peak-to-peak modulations of 4-5 $\mathrm{K}$ have been also observed during a strong storm (the most intense there in 25 years, which produced $S W H>4.5 \mathrm{~m}$ and caused severe damage to the platform structure), which cannot be predicted with current numerical methods and sea surface spectra. This large azimuthal signature can only be attributed to the presence of very thick foam patches in the downwind side of the waves. A detailed analysis of these results is published in [46].

Upwind-downwind and upwind-crosswind azimuthal dependence needs to be better estimated for moderate to high 
winds and sea-states, where the effect appears to be nonnegligible according to the model based on SSA proposed by Reul and Chapron [43]. No clear conclusions regarding this dependence were derived from the ESA-sponsored WISE [45], [46] and LOSAC [51] field experiments. The present conclusion is that the azimuthal signal is expected to be small but this requires confirmation by adequate experimental data.

Ocean wave spectra measured during WISE under growing or decreasing seas, or in presence of swell, clearly differ from the theoretical spectra computed from measured wind speed and the assumption of fully developed seas [47]. A practical description of the surface roughness, probably using a combination of wind and wave information, is therefore needed for use in forward models. An experimental fit of measured $T_{\mathrm{h}}$ and $T_{\mathrm{v}}$ to wind speed and significant wave height using the WISE data resulted in a semiempirical model that proved quite efficient at retrieving SSS [52]. Given the strong correlation existing between both variables, this result needs to be checked on future measurements. A similar approach can be used for SMOS and improve the selected theoretical model by fitting radiometric to in situ data after satellite launch.

WISE data also confirm a small, although nonnegligible impact of the presence of sea foam on the L-band brightness temperatures at wind speeds above $12 \mathrm{~m} / \mathrm{s}$. However, an important error source may be the fact that for the same wind conditions, the sea foam coverage exhibits large variability [45]. In the model proposed by Reul and Chapron (reported in [53]), foam effects have been incorporated through the combined use of a whitecap coverage dynamical model, including statistics for foam formations thickness [41], and a low-frequency asymptotic model for foam emissivity [54], but this solution needs to be validated by comparison with experimental data. A first detailed study by Etcheto et al. [23] using data from the EuroSTARRS campaign [55] indicates that the $T_{\mathrm{b}}$ using Monahan and Lu's empirical model for whitecap coverage [56], and Stogryn's model for foam emissivity [39], is by far too large. In spring 2003, a pond experiment (FROG) was carried out by UPC with the same radiometer used in WISE, to obtain data of the effect on $T_{\mathrm{b}}$ at L-band of foam coverage and thickness as a function of salinity. These (to date) unpublished data indicate a foam effect on $T_{\mathrm{b}}$ with salinities in the oceanic range that is in very good agreement with the Reul and Chapron model at $\mathrm{V}$-polarization for incidence angles below $40^{\circ}$, while above $45^{\circ}$ and for H-polarization at all angles the measured values are larger than modeled by $0.02-0.08 \mathrm{~K}$ [57].

The impact of rain at $1.4 \mathrm{GHz}$ on the brightness temperatures at satellite altitude has also been investigated [53]. Although the effects are small, they might be of importance because of the extreme sensitivity required of $T_{\mathrm{b}}$ to measure changes in surface salinity. Rain has two effects: attenuation of $T_{\mathrm{b}}$, which is reasonably well known at L-band (e.g., an attenuation coefficient of $10^{-3} \mathrm{~dB} / \mathrm{km}$ at $10 \mathrm{~mm} / \mathrm{h}$ for a total rain effect of $0.05 \mathrm{~K} / \mathrm{km}$ for a layer $5 \mathrm{~km}$ thick [25], [58]), and modification of sea surface roughness. The results of the FROG pond experiment [57] indicate an increase of 0.08 and $0.07 \mathrm{~K}$ brightness temperature increase at $\mathrm{H}$ - and $\mathrm{V}$-polarizations, respectively, at $25^{\circ}$ incidence angle for a $160-\mathrm{mm} / \mathrm{h}$ rain rate and are in good agreement with the predictions using the SSA method [57]. The impact in the brightness temperature due to the large wave damping by rain remains yet unknown. Since SSM/I data over $25-\mathrm{km}$ cells show that $10-\mathrm{mm} / \mathrm{h}$ rainfall only happens $0.25 \%$ of the time (see http://www.ssmi.com/ssmi/ssmi_browse.html), the impact of rain should not be large. Also, integration over the different SMOS footprint sizes should minimize the effect of rain in the case of light rain and inhomogeneous beam filling. For intense rainfall events, it will probably be necessary to flag and discard the radiometer data.

It is clear that there is a need to improve the modeling of the surface roughness and foam effects, since both are currently being modeled with an uncertainty larger than $1 \mathrm{~K}$. Dedicated campaigns to determine the L-band emissivity of sea water under different surface roughness conditions, and the study of factors (other than wind speed) influencing both surface waves and the foam coverage (difference in air and sea temperature, fetch, slicks, etc.), appear to be necessary to achieve the desired accuracy in SSS.

\section{SMOS SSS Error Budget}

Engineering studies of SMOS hardware indicate that the instrument should provide a radiometric accuracy of $1.2 \mathrm{~K}$ and sensitivity of $2.4 \mathrm{~K}$ (rms noise per 1.2-s snapshot) at instrument boresight [59]. Since the radiometric sensitivity is rather poor, it is clear that from a single pass, SSS cannot be recovered to the required accuracy. However, requirements for the measurement of SSS [9] can be met by averaging the SMOS individual measurements in both space and time, provided the number of independent samples available for averaging is large enough. This, evidently, will only reduce random errors, but not any systematic error present in the measurements. A different approach is needed to solve the problem of a bias or drift of the radiometer, probably by means of some kind of external calibration using known targets. A possibility is the so called "vicarious calibration" concept that uses a cold reference to check for instrument stability through a statistical method, as it was used for the TOPEX radiometer [60]. The averaging procedure requires excellent stability $(0.02 \mathrm{~K} /$ day $)$ and calibration of the radiometer receivers at a level that are technical challenges for SMOS.

Surface roughness is the major geophysical error source, as it can modify the measured $T_{\mathrm{b}}$ by several Kelvin depending on the incidence angle [8]. Unlike the Aquarius/SAC-D mission [10], SMOS does not carry any active instrument to determine roughness simultaneously with the $T_{\mathrm{b}}$ measurement. Auxiliary information will be needed to correct for this effect, as well as to obtain the values of sea surface temperature needed in the forward model. SST is not a major problem, since the maps generated at present from operational satellite missions (infrared, microwave radiometers, and combinations of them) are sufficient for the SSS retrieval [10]. However, the auxiliary variables that will be needed to parameterize the surface roughness (mainly wind and waves) are of critical importance. It has been demonstrated through numerical simulations [61] that the use of instantaneous wind speed improves significantly the retrieval of averaged SSS in GODAE-like boxes with respect to using averaged winds. In most occasions, the SMOS satellite overpasses will not coincide with other satellite sensors (radars) 
sampling simultaneously wind and waves over the same swath. Under such circumstances, sea state must be estimated somehow in the SSS retrieval algorithms using combined information from numerical weather and wave diagnostic models. To meet the GODAE requirements for SSS, any bias in the wind speed resulting from this procedure needs to be smaller than $0.2 \mathrm{~m} / \mathrm{s}$ at $10{ }^{\circ} \mathrm{C}$ [61].

Another possibility is the use of the SMOS measurements themselves to estimate the surface roughness. The multiangular character of these measurements, unlike classical radiometers at constant incidence, allows the possibility of retrieving wind speed and significant wave height, as well as SSS, from the brightness temperature. This has been demonstrated using the WISE data [24], [52] in which the values for these three variables are found that simultaneously minimize the cost function of the linear regression using a converging procedure [14]. These preliminary studies indicate that the quality of the retrieved SSS is likely to be higher if one does not use the available wind (and significant wave height if available) information in the computation, but rather as references (with their estimated accuracy) for further optimization by the retrieval algorithm. Even in the WISE case, a wind speed accuracy better than 1.5 $\mathrm{m} / \mathrm{s}$ is obtained when no auxiliary information is used [52]. This approach has to be checked for the SMOS configuration and in other oceanic regions.

The effects of the spatial and temporal variability, and uncertainty, of auxiliary data on the SSS retrieval have also been analyzed. For a satellite sensor whose footprint is $\sim 40 \times 40 \mathrm{~km}^{2}$ and revisit time is three days, smaller retrieval error can likely be obtained with $\sim 30$-day and $1^{\circ} \times 1^{\circ}$ averages than with ten-day and $2^{\circ} \times 2^{\circ}$ averages. Although the number of samples is similar, a recent study indicates that errors in auxiliary data (specifically SST and wind speed) are much more correlated in space than in time [43], so more error reduction is achieved by temporal averaging than by spatial averaging.

Other sources of error, besides those already mentioned (roughness, SST, rain), include Faraday rotation in the ionosphere, cloud liquid water, atmospheric absorption, solar reflection, galactic background radiation, and radio-frequency interference (RFI). In some cases, data should be discarded (sun glint, interference), and processing strategies can be implemented to avoid other errors (Faraday, RFI). Studies of the magnitude of these error sources and ways to mitigate their effects, by modeling or measuring them, are under development [8], [62]-[66]. Recent estimations indicate that with the exception of roughness effects, the rest of geophysical errors can have an impact on the SSS error budget of 0.15-0.30 psu for a single observation, depending on the latitude [10].

\section{Salinity Retrieval Algorithms}

The retrieval of SSS has additional complications in the case of SMOS. First of all, the interferometric radiometer involves an extra step of image reconstruction compared to conventional mapping radiometers that will entail a series of not fully known possible additional errors. Other aspects to be considered in the development of algorithms for salinity retrieval in the SMOS imaging configuration include the variable pixel size and possible existence of inhomogeneities within each pixel. The effect of inhomogeneity has been tested by modeling the effect of SST and SSS fronts and wind gradients in the resolution cell, and the impact of the location and size of each pixel within the satellite field of view. It was found that situations corresponding to cold waters and strong roughness fronts will be the most difficult conditions for salinity retrieval. (These unpublished results are included in the final report to ESA of a Salinity Data Processing Study in April 2003 [43]).

Tests of the salinity retrieval have been made considering several partial aspects of the problem. The uncertainty of retrieved SSS due to errors linked to noise on $T_{\mathrm{b}}$ and to noise on auxiliary parameters (mainly wind and SST) has been estimated, both on inversion using individual $T_{\mathrm{b}}$ and on inversion using the set of $T_{\mathrm{b}}$ 's measured in the SMOS configuration. Two inversion techniques that have been compared to retrieve salinity from the SMOS-measured brightness temperatures are neural networks and classical linear regression algorithms. The neural network algorithm does better with the nonlinear dependencies between salinity and brightness temperatures [43]. Whatever the method used, one key point for retrieval is assembling a representative database for SSS, SST, and wind speed. It has been demonstrated that using the $T_{\mathrm{b}}$ measured at various incidence angles greatly reduces the SSS error with respect to the use of a single measurement. In the SMOS configuration, simulating a retrieval of SSS at each satellite pass (with instantaneous wind field applied to a two-scale emissivity model) the error on the SSS averaged over ten days and $200 \times 200 \mathrm{~km}^{2}$ is less than 0.1 psu [61], which is the SMOS goal for operational applications over the global ocean except close to ice edges and some coastal areas (Fig. 4). For this preliminary estimate, errors due to image reconstruction were neglected, and it was assumed that all the errors are uncorrelated.

Gathering all available empirical data on L-band sea surface emissivity (Hollinger, Swift, Webster, WISE, JPL data, LOSAC, and EuroSTARRS) reveal that the sensitivity of the sea surface brightness temperature to wind speed is known approximately with uncertainties of about $0.15 \mathrm{~K} /(\mathrm{m} / \mathrm{s})$ and $0.1 \mathrm{~K} /(\mathrm{m} / \mathrm{s})$, at $\mathrm{H}$ and $\mathrm{V}$-polarizations, respectively, and for the range of incidence angles useful for SMOS $\left(0^{\circ}\right.$ to $\left.55^{\circ}\right)$. As shown in [8], the sensitivity of brightness temperature to SSS at L-band for a calm sea surface is in the range $0.2-0.6 \mathrm{~K} / \mathrm{psu}$ for horizontal polarization and $0.35-0.8 \mathrm{~K} / \mathrm{psu}$ for vertical polarization. Accordingly, if empirical fits with the reported uncertainties are used to estimate the correction for roughness, SSS retrieval errors in the range $0.8-5$ psu (depending on SST, incidence angle, and polarization) are expected for a single pass and single incidence angle at $7-\mathrm{m} / \mathrm{s}$ wind speed.

When applying an empirical inversion algorithm for wind dependence based on WISE data to retrieve SSS and using $T_{\mathrm{b}}$ measured independently during the WISE campaign, the average retrieved SSS exhibits a bias of $0.52 \mathrm{psu}$ and a standard deviation of 0.12 psu [24], (Fig. 5). As expected, the retrieval error decreases with increasing number of data points (incidence angles). In this case, the empirical inversion algorithm performed better than an algorithm based on theoretical emissivity models (Two-scale, SSA/SPM with Durden-Vesecky, Elfouhaily) [24]. However, the empirical model has been optimized for the 


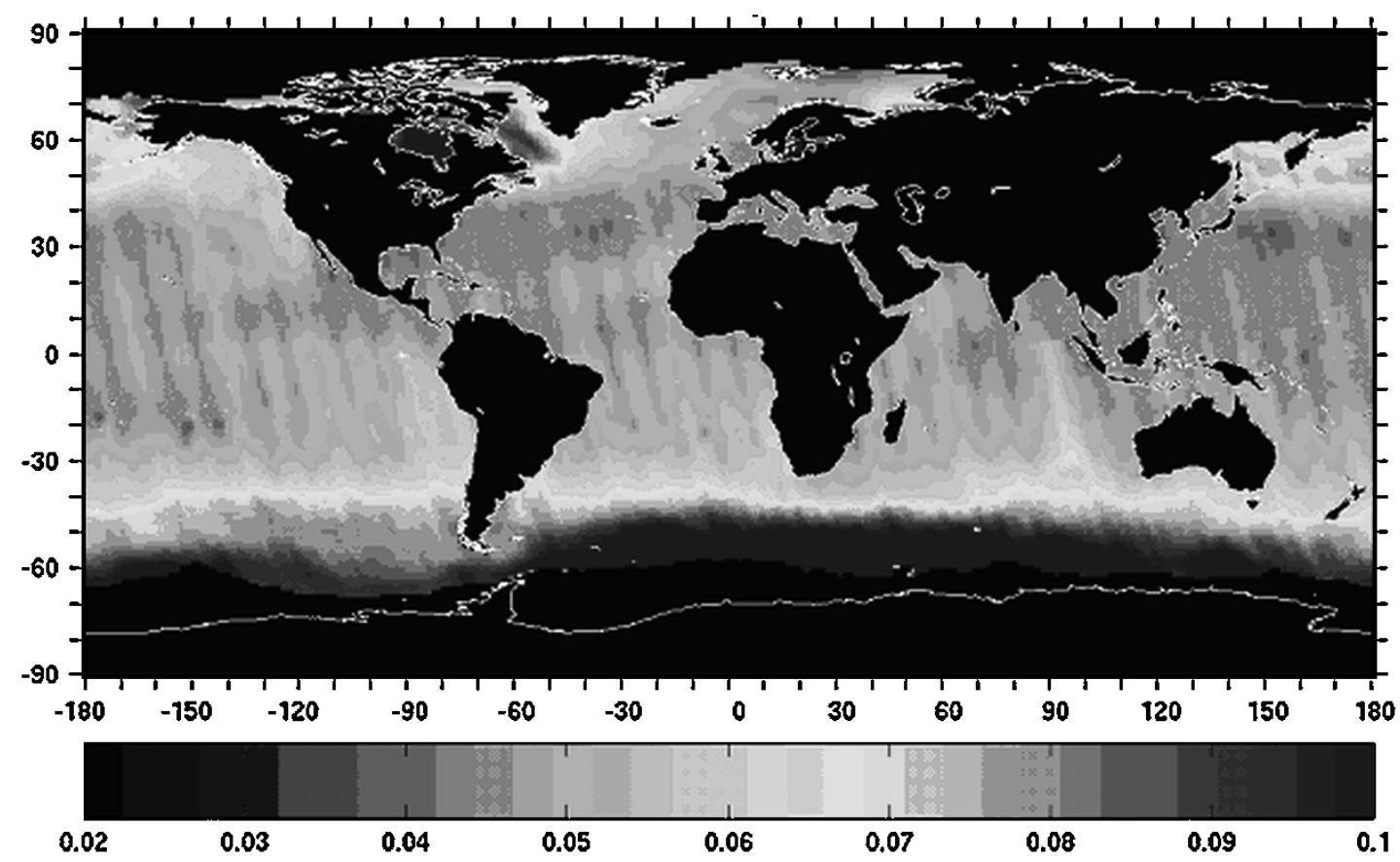

Fig. 4. Error on the SSS measured by SMOS averaged over ten days and $200 \mathrm{~km} \times 200 \mathrm{~km}$ boxes from a simulation using the SMOS configuration and expected performances. Uncertainties in auxiliary data are $2 \mathrm{~m} / \mathrm{s}$ for wind speed and $1^{\circ} \mathrm{C}$ for SST. Other geophysical errors, as well as errors due to image reconstruction or calibration stability, are not considered. The resulting averaged error ranges from 0.1 psu in polar regions to below 0.05 psu in most open-ocean areas. From Boutin et al. (report included in [53]).

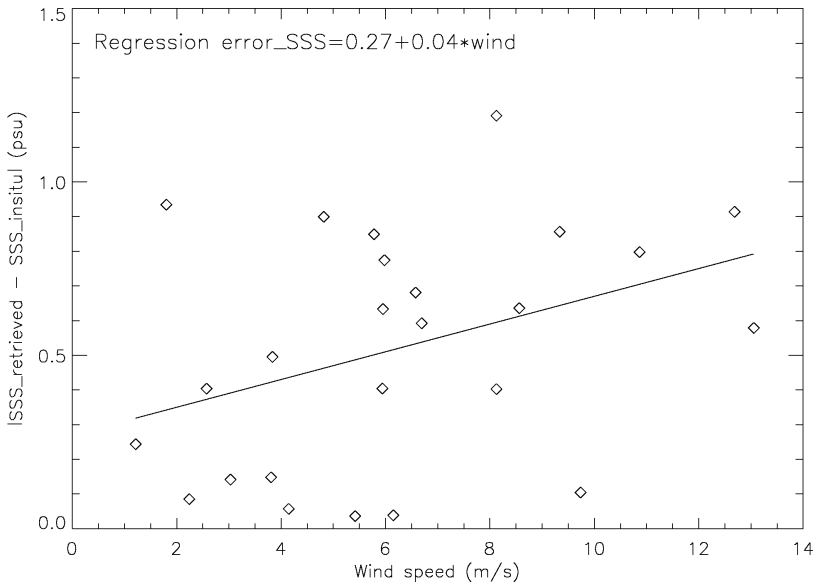

Fig. 5. Error as function of the wind speed in the salinity retrieved from L-band polarimetric measurements during the WISE 2001 campaign. The forward emissivity model used is the one derived from the data collected during the campaign as shown in the previous figure. Redrawn from Gabarró et al. [24].

specific environment of the WISE experiment (shelf break in the northwest Mediterranean) and likely will need to be modified for application to other ocean regions.

A recent study performed by Gabarro et al. [52] reveals that including significant wave height in addition to wind speed in the empirical inversion algorithm significantly improve the SSS retrieval accuracy ( 0.33 psu bias compared to 0.52 above). Such improvement might be expected in general when using empirical inversion algorithms, since the sensitivity of $T_{\mathrm{b}}$ to wind speed is certainly correlated in some manner to sea state. This 0.33 psu only degrades to 0.44 psu when using the first Stokes parameter $I=T_{\mathrm{h}}+T_{\mathrm{v}}$ instead of the two polarizations $T_{\mathrm{h}}$ and $T_{\mathrm{v}}$ separately (and thus reducing the data points by $50 \%$ ). The use of the first Stokes parameter has been proposed as a way to eliminate Faraday rotation effects [61], [64], [65], while at the same time minimizes errors in the model for dielectric constant and effect of swell [64]. When the WISE-derived model using wind and waves was applied to L-band $T_{\mathrm{v}}$ airborne data recorded during the EuroSTARRS campaign during a straight line flight in the Mediterranean sea (800 data points), the average salinity was recovered with an uncertainty of only 0.13 psu [52].

SSS retrieval algorithms for SMOS have also been tested using the SMOS End-to-end Performance Simulator (SEPS) [67]. It is found that in most cases an ideal instrument without spatial averaging can achieve the 0.1 psu SSS accuracy goal with 30-day temporal averaging. Only in one out of four cases studied, with strong winds and rapid SSS and SST variations, was the SSS accuracy poorer ( $0.2 \mathrm{psu})$. However, to achieve this goal, instrumental biases must be kept to a very low level $\left(I_{\text {bias }}<0.22 \mathrm{~K}\right)$, and geophysical modeling errors (e.g., dielectric constant model and correction for wind speed) must also be very low and by themselves can lead to noncompliance of the 0.1 psu goal [64], [68]. A recent study with SEPS (at SMOS Phase B configuration and using the first Stokes parameter) that takes into account thermal noise, all instrumental error sources, current error-correction and image reconstruction algorithms, and correction for atmospheric and sky noises (as well as an external calibration technique to correct for $T_{\mathrm{b}}$ biases at each satellite overpass) shows a 30-day averaged SSS retrieval at SMOS pixel size with an error of 0.1-0.3 psu in three different cases analyzed [69].

The requirements on radiometer stability to achieve the SMOS goal of 0.1 psu imply that besides the on-board and "vicarious" instrument calibration, a detailed calibration/validation strategy 
has to be set up to continuously correct for any drift. The use of in situ measurements, e.g., made by moored or drifting buoys, profiling floats, and ships, has to be carefully organized in this strategy. This requires analysis of possible effects because these in situ measurements are usually made at a few meters below the surface ( $5 \mathrm{~m}$ standard in profiling floats) to avoid problems of fouling in the conductivity sensors. Large homogeneous areas of ocean, but with contrasted radiometric characteristics, will be of great use to obtain the required in situ information and should be the object of dedicated deployments. In this respect, the cooperation of SMOS with Aquarius/SAC-D, which has already begun in the design of the Aquarius/SAC-D cal/val plan, will be of maximum value.

\section{CONCLUSION}

The SMOS exploratory field experiments (WISE, LOSAC, and EuroSTARRS) have provided some key preliminary results on the sensitivity of $T_{\mathrm{b}}$ to important surface parameters. These include effects of wind speed as a function of incidence angle, the validity of theoretical models for emissivity (below and above $3 \mathrm{~m} / \mathrm{s}$ ), the performance of empirical models in salinity retrieval, at least in the case of WISE, the unresolved dependence on azimuth angle, and the importance of the still unknown effect of foam coverage as a function of wind speed. Theoretical studies have given new insight into different aspects to be considered in the SMOS data processing and on the expected impact of SMOS data in ocean circulation models.

In September 2003, the ESA Programme Board for Earth Observation voted unanimously to proceed with the SMOS phases $\mathrm{C}$ and $\mathrm{D}$ (detailed design and implementation of the mission), so that the scheduled launch for 2007 is likely to be assured. Before then, the open questions regarding the retrieval of SSS from SMOS radiometric measurements have to be closed. This will have to be accomplished by means of further theoretical studies and data obtained in new experiments and field campaigns. The latter should include the use of airborne interferometric radiometer demonstrators now under preparation and expected to be ready in 2005 .

The main issue now is to improve the knowledge of the effect of roughness on the emissivity. This needs to include the dependence on incidence angle and polarization and include the effects of wind/wave direction, foam, and rain, as well as wind speed. It is also necessary to resolve the uncertainty in the model function (dependence on salinity and temperature) for the dielectric constant of sea water. Based on understanding these issues, it is necessary to develop an operational forward model for sea surface emissivity under the different environmental conditions. Other relevant aspects to be achieved are the development of efficient algorithms to retrieve SSS maps from $T_{\mathrm{b}}$, which include the use of auxiliary information (data/models for wind, waves, SST, etc.), plus temporal and spatial averaging procedures; the design of strategies to validate the SMOS salinity products with oceanographic measurements in adequate areas; and the development of assimilation schemes for SMOS data into ocean circulation models.

\section{ACKNOWLEDGMENT}

The authors wish to acknowledge the members of the teams that performed the SMOS-dedicated ESA studies and campaigns, the SMOS Science Advisory Group, and all scientists and technologists on both sides of the Atlantic that made possible all this advancement on salinity measurement from satellite. Comments from three referees helped in improving the manuscript.

\section{REFERENCES}

[1] P. Sivestrin, M. Berger, Y. Kerr, and J. Font, "ESA's second earth explorer opportunity mission: The soil moisture and ocean salinity mission-SMOS," IEEE Geosci. Remote Sensing Newslett., vol. 118, pp. 11-14, Mar. 2001.

[2] M. Martín-Neira and J. M. Goutoule, "A two-dimensional aperture-synthesis radiometer for soil moisture and ocean salinity observations," ESA Bull., vol. 92, pp. 95-104, 1997.

[3] L. A. Klein and C. T. Swift, "An improved model for the dielectric constant of sea water at microwave frequencies," IEEE J. Oceanic Eng., vol. 2, pp. 104-111, 1977.

[4] G. S. E. Lagerloef, C. T. Swift, and D. M. LeVine, "Sea surface salinity: The next remote sensing challenge," Oceanography, vol. 8, pp. 44-50, 1995.

[5] Y. Kerr, P. Waldteufel, J. P. Wigneron, J. M. Martinuzzi, J. Font, and M. Berger, "Soil moisture retrieval from space: The Soil Moisture and Oean Slinity (SMOS) mission," IEEE Trans. Geosci. Remote Sensing, vol. 39, pp. 1729-1735, Aug. 2001.

[6] J. D. Kraus, Radio Astronomy. Delaware, OH: Cygnus-Quasar, 1986.

[7] A. Camps and C. T. Swift, "New techniques in microwave radiometry for earth remote sensing," in Review of Radio Science 1999-2002, W. R. Stone, Ed. Piscataway, NJ: IEEE Press, 2002, pp. 499-518.

[8] S. H. Yueh, R. West, W. J. Wilson, F. K. Li, E. G. Njoku, and Y. RahmatSamii, "Error sources and feasibility for microwave remote sensing of ocean surface salinity," IEEE Trans. Geosci. Remote Sensing, vol. 39, pp. 1049-1060, May 2001.

[9] G. S. E. Lagerloef, "Recent progress toward satellite measurements of the global sea surface salinity field," in Satellites, Oceanography, and Society, D. Halpern, Ed. Amsterdam, The Netherlands: Elsevier, 2000, pp. 309-319.

[10] C. J. Koblinsky, P. Hildebrand, D. M. Le Vine, F. Pellerano, Y. Chao, W J. Wilson, S. Yueh, and G. S. E. Lagerloef, "Sea surface salinity from space: Science goals and measurement approach," Radio Sci., vol. 38, p. 8064, 2003. DOI:10.1029/2001RS002584.

[11] J. Font, G. S. E. Lagerloef, Y. Kerr, N. Skou, and M. Berger, "Sea surface salinity mapping with SMOS space mission," in Building the European Capacity in Operational Oceanography. Proc. 3rd EuroGOOS Conf. ser. Elsevier Oceanography Series, H. Dahlin, N. C. Flemming, K. Nittis, and S. E. Petterson, Eds. Amsterdam, The Netherlands: Elsevier, 2003, vol. 69, pp. 186-189.

[12] N. Smith and M. Lefèbvre, "The global ocean data assimilation experiment (GODAE)," in Proc. Int. Symp. Monitoring Oceans in the 2000s: An Integrated Approach, Biarritz, France, 1997.

[13] S. Levitus, R. Burgett, and T. P. Boyer, World Ocean Atlas 1994. Silver Spring, MD: NOAA NESDIS, 1994, vol. 3, Salinity.

[14] P. Waldteufel, J. Boutin, and Y. Kerr, "Selecting an optimal configuration for the SMOS mission," Radio Sci., vol. 38, p. 8051, 2003. DOI 10.1029/2002RS002744

[15] W. Ellison, A. Balana, G. Delbos, K. Lamkaouchi, L. Eymard, C. Guillou, and C. Prigent, "New permittivity measurements of sea water," Radio Sci., vol. 33, pp. 639-648, May-June 1998.

[16] E. Dinnat, J. Boutin, G. Caudal, J. Etcheto, and P. Waldteufel, "Influence of sea surface emissivity model parameters in L-band for the estimation of salinity," Int. J. Remote Sens., vol. 23, pp. 5117-5122, 2002.

[17] W. J. Wilson, S. H. Yueh, S. J. Dinardo, S. L. Chazanoff, A. Kitiyakara, F. K. Li, and Y. Rahmat-Samii, "Passive active L- and S-band (PALS) microwave sensor for ocean salinity and soil moisture measurements," IEEE Trans. Geosci. Remote Sensing, vol. 39, pp. 1039-1048, May 2001

[18] W. J. Wilson, S. H. Yueh, S. Dinardo, and F. K. Li, "High stability L-band radiometer measurements of saltwater," IEEE Trans. Geosci. Remote Sensing, vol. 42, pp. 1829-1835, Sept. 2004. 
[19] S. Blanch and A. Aguasca, "Sea water dielectric permittivity models: Review and impact on the brightness temperature at L-band," in Proc. SMOS Campaigns Workshop, 2003, ESA SP-525, pp. 137-141.

[20] R. H. Lang, C. Utku, and D. M. Le Vine, "Measurement of the dielectric constant of seawater at L-band," in Proc. IGARSS, vol. I, Toulouse, France, 2003, pp. 19-21.

[21] E. Dinnat, J. Boutin, G. Caudal, and J. Etcheto, "Issues concerning the sea emissivity modeling in L-band for retrieving surface salinity," Radio Sci., vol. 38, p. 8060, 2003. DOI: 10.1029/2002RS002637.

[22] M. Vall-Llossera, J. Miranda, A. Camps, and R. Villarino, "Sea surface emissivity modeling at L-band: An intercomparison study," in Proc. SMOS Campaigns Workshop, 2003, ESA SP-525, pp. 143-153.

[23] J. Etcheto, E. Dinnat, J. Boutin, A. Camps, J. L. Miller, S. Contardo, J. Wesson, J. Font, and D. Long, "Recent L-band models validation using EuroSTARRS and WISE 2001 campaigns," IEEE Trans. Geosci. Remote Sensing, Oct. 2004.

[24] C. Gabarró, M. Vall-Llossera, J. Font, and A. Camps, "Determination of the sea surface salinity and wind speed by L-band microwave radiometry from a fixed platform," Int. J. Remote Sens., vol. 25, pp. 111-128, 2004.

[25] F. Ulaby, R. Moore, and A. Fung, Microwave Remote Sensing. Active and Passive. Reading, MA: Addison-Wesley, 1982, vol. III, Radar Remote Sensing and Surface Scattering and Emission Theory.

[26] V. G. Irisov, "Small-slope expansion for thermal and reflected radiation from a rough surface," Waves Random Media, vol. 7, pp. 1-10, 1997.

[27] J. T. Johnson and M. Zhang, "Theoretical study of the small slope approximation for ocean polarimetric thermal emission," IEEE Trans. Geosci. Remote Sensing, vol. 37, pp. 2305-2316, Sept. 1999.

[28] F. Wentz, "A two-scale model for foam-free sea microwave brightness temperature," J. Geophys. Res., vol. 80, pp. 3441-3446, 1975.

[29] S. H. Yueh, "Modeling of wind direction signals in polarimetric sea surface brightness temperatures," IEEE Trans. Geosci. Remote Sensing, vol. 35, pp. 1400-1418, Nov. 1997

[30] A. Stogryn, "The apparent temperature of the sea at microwave frequencies," IEEE Trans. Antennas Propagat., vol. AP-15, pp. 278-286, Jan. 1967.

[31] D. B. Kunkee and A. J. Gasiewski, "Simulation of passive microwave wind direction signatures over the ocean using an asymmetric-wave geometrical optics model," Radio Sci., vol. 32, pp. 59-78, 1997.

[32] A. Camps, I. Corbella, and J. M. Rius, "Extension of Kirchhoff method under stationary phase approximation to determination of polarimetric thermal emission of the sea," Electron. Lett., vol. 34, pp. 1501-1503, 1998.

[33] A. K. Fung, Microwave Scattering and Emission. Models and Their Applications. Boston, MA: Artech House, 1994.

[34] J. L. Alvarez-Pérez, "An extension of the IEM/IEMM surface scattering model," Waves Random Media, vol. 11, pp. 307-329, 2001.

[35] S. Durden and J. Vesecky, "A physical radar cross-section model for a wind-driven sea with swell," IEEE J. Oceanic Eng., vol. 10, pp. 445-451, Oct. 1985.

[36] T. Elfouhaily, B. Chapron, K. Katsaros, and D. Vandermark, "A unified directional spectrum for long and short wind-driven waves," J. Geophys. Res., vol. 102, pp. 15 781-15 796, 1997.

[37] V. N. Kudryavtsev, V. K. Makin, and B. Chapron, "Coupled sea surface-Atmosphere model. 2. Spectrum of short wind waves," J. Geophys. Res., vol. 104, pp. 7625-7639, 1999.

[38] T. T. Wilheit, "A model for the microwave emissivity of the ocean's surface as a function of wind speed," IEEE Trans. Geosci. Electron., vol. GE-16, pp. 244-249, 1979.

[39] A. Stogryn, "The emissivity of sea foam at microwave frequencies," $J$. Geophys. Res., vol. 77, pp. 1658-1666, 1972.

[40] P. M. Smith, "The emissivity of sea foam at 19 and $37 \mathrm{GHz}$," Int. J. Remote Sens., vol. 26, no. 5, pp. 541-547, 1988.

[41] N. Reul and B. Chapron, "A model of sea-foam thickness distribution for passive microwave remote sensing applications," J. Geophys. Res., vol. 108, p. 3321, 2003. DOI: 10.1029/2003JC001887.

[42] R. Villarino, A. Camps, M. Vall-Llossera, J. Miranda, and J. Arenas, "Sea foam and sea state effects on the instantaneous brightness temperatures at L-band," in Proc. SMOS Campaigns Workshop, 2003, ESA SP-525, pp. 95-103.

[43] O. Z. Zanifé, N. Reul, B. Chapron, E. Obligis, C. Boone, S. Labroue, H. Sagen, and G. Evensen, "SMOS salinity data processing study," CLS, Toulouse, France, ESA Contract 15165/01/NL/SF, Rep. CLS-IFREMER-NERSC, 2003.

[44] T. Elfouhaily, S. Guignard, R. Awadallah, and D. Thompson, "Local and nonlocal curvature approximation: A new asymptotic theory for wave scattering," Waves Random Media, vol. 13, pp. 321-337, 2003.
[45] A. Camps, J. Font, J. Etcheto, V. Caselles, A. Weill, I. Corbella, M. Vall-Llossera, N. Duffo, F. Torres, R. Villarino, L. Enrique, A. Julià, C. Gabarrò, J. Boutin, E. Rubio, S. C. Reising, P. Wursteisen, M. Berger, and M. Martìn-Neira, "Sea surface emissivity observations at L-band: First results of the wind and salinity experiment WISE 2000," IEEE Trans. Geosci. Remote Sensing, vol. 40, pp. 2117-2130, Oct. 2002.

[46] A. Camps, J. Font, M. Vall-Llossera, C. Gabarró, I. Corbella, N. Duffo, F. Torres, S. Blanch, A. Aguasca, R. Villarino, L. Enrique, J. Miranda, J. Arenas, A. Julià, J. Etcheto, V. Caselles, A. Weill, J. Boutin, S. Contardo, R. Niclós, R. Rivas, S. C. Reising, P. Wursteisen, M. Berger, and M. Martín-Neira, "The WISE 2000 and 2001 field experiments in support of the SMOS mission: Sea surface L-band brightness temperature observations and their application to sea surface salinity retrieval," IEEE Trans. Geosci. Remote Sensing, vol. 42, pp. 804-823, Apr. 2004.

[47] J. Miranda, M. Vall-Llossera, A. Camps, N. Duffo, and J. Etcheto, "Sea state effect on the sea surface emissivity at L-band," IEEE Trans. Geosci. Remote Sensing, vol. 41, pp. 2307-2315, Oct. 2003.

[48] J. P. Hollinger, "Passive microwave measurements of sea surface roughness," IEEE Trans. Geosci. Electron., vol. GE-9, pp. 165-169, 1972.

[49] D. M. Le Vine, S. S. Søbjærg, N. Skou, W. J. Wilson, S. Yueh, S. Dinardo, E. Kim, D. Pellerano, J. Piepmeier, P. Racette, and A. Camps, "Small scale fluctuations observed in L-band radiometer measurements of the ocean," in Minutes of a Working Group Meeting, Goddard Space Flight Center. Greenbelt, MD: NASA, Nov. 2003.

[50] W. J. Webster, T. T. Wilheit, D. B. Ross, and P. Gloersen, "Spectral characteristics of the microwave emission from a wind-driven foam covered sea," J. Geophys. Res., vol. 81, pp. 3095-3099, 1976.

[51] S. S. Søbjærg, J. Rotbøll, and N. Skou, "Wind effects and angular dependence at L-band polarimetric data: First results of LOSAC," in Proc. SMOS Campaigns Workshop, 2003, ESA SP-525, pp. 181-189.

[52] C. Gabarró, J. Font, A. Camps, M. Vall-Llossera, and A. Julià, "A new empirical model of sea surface microwave emissivity for salinity remote sensing," Geophys. Res. Lett., vol. 31, p. L01309, 2004. DOI: 10.1029/2003GL018964.

[53] J. A. Johannessen, B. Barnier, M. Bentsen, C. Boone, J. P. Boulanger, J. Boutin, A. Camps, B. Chapron, H. Drange, M. Espino, J. Font, T. Furevik, M. Garcia, C. Gommenginger, A. Guissard, G. Larnicol, D. Lemaire, N. Martin, J. M. Molines, P. Y. Le Traon, E. Obligis, N. Reul, J. Schulz, M. Sébastien, P. Sobieski, M. Srokosz, and J. Verron, "Scientific requirements and impact of space observations of ocean salinity for modeling and climate studies," NERSC, Bergen, Norway, ESA Contract 14273/00/NL/DC, NERSC Rep. 214, 2002.

[54] L. A. Dombrovskiy and V. Y. Raizer, "Microwave model of a two phase medium at the ocean surface," Izv. Atmos. Oceanic Hys., vol. 28, pp. 650-656, 1992.

[55] M. Berger, A. Camps, J. Font, Y. Kerr, J. L. Miller, J. Johannessen, J. Boutin, M. R. Drinkwater, N. Skou, N. Floury, M. Rast, H. Rebhan, and E. Attema, "Measuring ocean salinity with ESA's SMOS mission-Advancing the science," ESA Bull., vol. 111, pp. 113-121, 2002.

[56] E. C. Monahan and M. Lu, "Acoustically relevant bubble assemblages and their dependence on meteorological parameters," IEEE J. Oceanic Eng., vol. 15, pp. 340-349, Oct. 1990.

[57] A. Camps, M. Vall-Llossera, R. Villarino, R. Rodríguez, R. Sabia, S. Monerris, I. Corbella, N. Duffo, and F. Torres, "Foam-covered and rainroughned sea surface emissivity at L-band: Results from the FROG 2003 experiment," in Proc. 8th Specialist Meeting Microwave Radiometry and Remote Sensing Applications, Rome, Italy, 2004.

[58] D. E. Setzer, "Computed transmission through rain at microwave and visible frequencies," Bell Syst. Tech. J., Oct. 1970.

[59] A. Camps, I. Corbella, F. Torres, M. Vall-Llossera, and N. Duffo, "SMOS-PLM technical note on SMOS system performance model and error budget," Univ. Politècnica de Catalunya,, Barcelona, Spain, SO-TN-UPC-PLM-02 rev 3.20, Nov. 6, 2003.

[60] C. S. Ruf, "Detection of calibration drifts in spaceborne microwave radiometers using a vicarious cold reference," IEEE Trans. Geosci. Remote Sensing, vol. 38, pp. 44-52, Jan. 2000.

[61] J. Boutin, P. Waldteufel, N. Martin, G. Caudal, and E. Dinnat, "Surface salinity retrieved from SMOS measurements over the global ocean: Imprecisions due to sea surface roughness and temperature uncertainties," J. Atmos. Oceanic Technol., vol. 21, pp. 1432-1447, Sept. 2004.

[62] D. M. Le Vine and S. Abraham, "Galactic noise and passive microwave remote sensing from space at L-band," IEEE Trans. Geosci. Remote Sensing, vol. 42, pp. 119-129, Jan. 2004.

[63] _ "The effect of the ionosphere on remote sensing of sea surface salinity from space: Absorption and emission at L-band," IEEE Trans. Geosci. Remote Sensing, vol. 40, pp. 771-782, Apr. 2002. 
[64] A. Camps, I. Corbella, M. Vall-Llossera, N. Duffo, F. Torres, R. Villarino, L. Enrique, F. Julbe, J. Font, A. Julià, C. Gabarró, J. Etcheto, J. Boutin, A. Weill, E. Rubio, V. Caselles, P. Wursteisen, and M. MartínNeira, "L-band sea surface emissivity: Preliminary results of the WISE2000 campaign and its application to salinity retrieval in the SMOS mission," Radio Sci., vol. 38, p. 8071, 2003. DOI: 10.1029/2002RS002629.

[65] N. Skou, "Faraday rotation and L band oceanographic measurements," Radio Sci., vol. 38, p. 8059, 2003. DOI: 10.1029/2002RS002671.

[66] P. Waldteufel, N. Floury, E. Dinnat, and G. Caudal, "Ionospheric effects for L-band 2-D interferometric radiometry," IEEE Trans. Geosci. Remote Sensing, vol. 42, pp. 105-118, Jan. 2004.

[67] I. Corbella, A. Camps, M. Zapata, F. Marcos, F. Martínez, M. Vall-Llossera, N. Duffo, and J. Bará, "End-to-end simulator of 2D interferometric radiometry," Radio Sci., vol. 38, p. 8058, 2003. DOI: $10.1029 / 2002 R S 002665$.

[68] A. Camps, N. Duffo, M. Vall-Llossera, and B. Vallespín, "Sea surface salinity retrieval using multi-angular L-band radiometry: Numerical study using the SMOS end-to-end performance simulator," in Proc. IGARSS, Toronto, ON, Canada, 2002.

[69] A. Camps, M. Vall-Llossera, L. Batres, F. Torres, N. Duffo, and I. Corbella, "Retrieving sea surface salinity with multi-angular L-band brightness temperatures: Improvement by spatio-temporal averaging," Radio Sci., 2004, to be published.

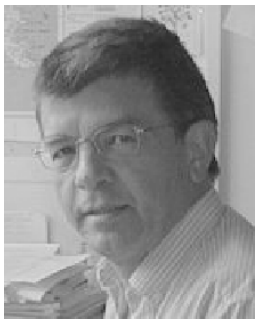

Jordi Font received the Licenciado and Ph.D. degrees in physics from the Universitat de Barcelona, Barcelona, Spain, in 1973 and 1986, respectively.

$\mathrm{He}$ is currently a Senior Researcher at the Institut de Ciències del Mar (CSIC), Barcelona, Spain, since 1991, and is responsible for the Physical Oceanography Group since 1987 . He is the author and coauthor of 215 communications to scientific symposia and 95 published papers. He is Adviser of several $\mathrm{Ph} . \mathrm{D}$. theses. He is a Principal Investigator for several Spanish and European research contracts. His main research activities are physical oceanography; the study of the marine circulation in the western Mediterranean from hydrographic, current-meter (vessel mounted, moored, and drifting), and satellite measurements; variability and dynamics of the ocean surface layer and shelf-slope exchange processes; and the use of remote sensing of the oceans in studying the marine circulation and dynamics. He is currently Co-Lead Investigator for ocean salinity in the European Space Agency SMOS mission.

Dr. Font is a member of several international societies and committees and has participated in 42 oceanographic campaigns.

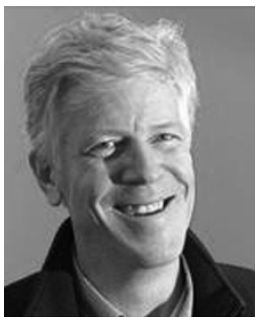

Gary S. E. Lagerloef received the B.S. degree from the Florida Institute of Technology, Melbourne, in 1971, the M.S. degree in oceanography from the University of Connecticut, Storrs, in 1975, and the $\mathrm{Ph} . \mathrm{D}$. degree in physical oceanography from the University of Washington, Seattle, in 1984.

From 1972 to 1975 , he served in the U.S. Coast Guard, where he taught marine science at the Coast Guard Academy. From 1976 to 1985, he was with the National Oceanic and Atmospheric Administration, about half that time as a Seagoing Officer on research ships in the Pacific and half at the Pacific Marine Environmental Laboratory (PMEL) in Seattle. He later worked in private sector marine science. From 1988 to 1990, he served as Physical Oceanography Program Manager with the National Aeronautics and Space Administration (NASA), Washington, DC, in the ocean science remote sensing program. In 1995, he cofounded Earth and Space Research, a nonprofit scientific institution in Seattle, where he has developed several research projects devoted to studies of the upper ocean dynamics and climate variability using satellites. In December 2003, he was appointed by NASA to lead the Aquarius satellite mission as Principal Investigator (launch date in 2008). He played a major role in gaining approval for this program, which will help study the interactions between the ocean circulation, global water cycle, and climate by measuring ocean salinity from space.

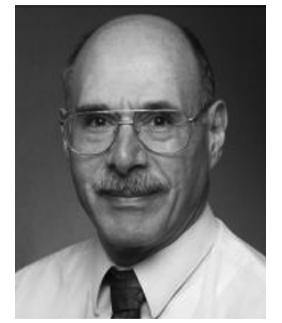

David M. Le Vine (M'70-SM'79-F'95) received the B.S. and M.S. degrees in electrical engineering, the M.S. degree in physics, and the Ph.D. degree in electrical engineering from the University of Michigan, Ann Arbor.

$\mathrm{He}$ has been an Electronics Engineer at the Harry Diamond Laboratory, Department of the Army, and a Research Engineer at the Radiation Laboratory, University of Michigan. After leaving the University of Michigan, he became an Assistant Professor in the Department of Electrical Engineering, University of Maryland, College Park. In 1973, he joined NASA's Goddard Space Flight Center, Greenbelt, MD, where he is currently a member of the Microwave Sensors Branch. His current research has focused on the development of techniques for microwave remote sensing of the environment from space.

Dr. Le Vine is a member of the International Union of Radio Science (URSI, Commisions B, E, and F) and the American Geophysical Union. He is affiliated with the IEEE Antennas and Propagation Society and the IEEE Geoscience and Remote Sensing Society. He was President of the local (Washington, DC) section of the IEEE Antennas and Propagation Society and has been active in engineering accreditation. He was a member of the IEEE Committee on Engineering Accreditation Activities (CEAA) and one of the IEEE representatives on the Engineering Accreditation Commission (EAC) of ABET. He is a member of Eta Kappa Nu, Tau Beta Pi, and Phi Kappa Phi. He was a University of Michigan Fellow and NASA/ASEE Faculty Fellow and is the recipient of several service awards from the Goddard Space Flight Center.

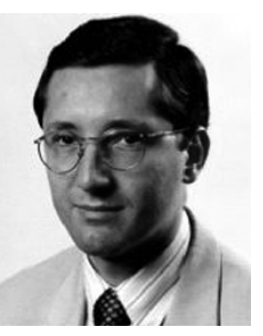

Adriano Camps (S'91-A'97-M'00-SM'02) was born in Barcelona, Spain, in 1969. He received the Telecommunications Engineering degree and the $\mathrm{Ph} . \mathrm{D}$. degree in telecommunications engineering in 1992 and 1996, respectively, both from the Polytechnic University of Catalonia (UPC), Barcelona, Spain.

From 1991 to 1992, he was with the ENS des Télécommunications de Bretagne, Bretagne, France, with an Erasmus Fellowship. In 1993, he joined the Electromagnetics and Photonics Engineering group, at the Department of Signal Theory and Communications, UPC, as an Assistant Professor, and since 1997 as an Associate Professor. In 1999, he was on sabbatical leave at the Microwave Remote Sensing Laboratory, University of Massachusetts, Amherst. His research interests are microwave remote sensing, with special emphasis in microwave radiometry by aperture synthesis techniques. He has performed numerous studies within the frame of European Space Agency SMOS Earth Explorer Mission. He is an Associate Editor of Radio Science.

Dr. Camps received the second national award of university studies in 1993, the INDRA award of the Spanish Association of Telecommunication Engineering to the best Ph.D. in 1997, the extraordinary Ph.D. award at the Universitat Politècnica de Catalunya in 1999, the First Duran Farell Award and the Ciudad de Barcelona Award, in 2000 and 2001, respectively, both for Technology Transfer, in 2002, the Research Distinction of the Generalitat de Catalunya for contributions to microwave passive remote sensing, in 2003 , the Premi Nacional de Telecomunicacions (Generalitat de Catalunya) with the members of the Electromagnetics and Photonics Engineering group, and in 2004 the Salvà i Campillo Award of the Telecommunications (Engineering College of Catalonia) to the most innovative research project, jointly with the rest of the Microwave Radiometry group. He was Chair of Cal ' 01 . He is editor of the IEEE Geoscience and Remote Sensing Newsletter and President-Founder of the IEEE Geoscience and Remote Sensing Society Spain Chapter.

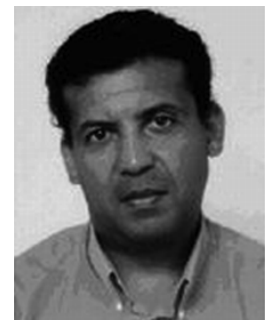

Ouan-Zan Zanifé received the B.S. degree in physics and the M.S. and Ph.D. degrees in remote sensing from the University of Paris VII, Paris, France, in 1983, 1984, and 1992, respectively.

He joined the Collecte, Localisation, Satellites (CLS), Ramonville Saint-Agne, France, in 1990, and was in charge of the ground processing and in-flight validation of the POSEIDON-1 radar altimeter data. Since then, he has continued to work on the Jason-1 and ENVISAT radar altimeter and radiometer missions. He is currently the Head of the Ground Processing Unit, Space Oceanography Division, CLS, and is involved in studies dealing with GPS studies, SMOS, CRYOSAT, and Jason-2 missions. 